Research Article

\title{
Screening Higher Secondary School Adolescents for Factors Contributing to Stress in Pune City
}

\author{
Mahima Shah', Suroshree Mitra ${ }^{2}$, Rachana Dabadghav ${ }^{3}$ \\ ${ }^{1}$ Bachelor of Physiotherapy, ${ }^{3}$ Research Co-ordinator, Sancheti College of Physiotherapy, Pune, Maharashtra, India. \\ ${ }^{2}$ Associate Professor, Department of Community Physiotherapy, Sancheti College of Physiotherapy, Pune, Maharashtra, India. \\ DOI: https://doi.org/10.24321/2349.2880.201914
}

\section{I $\quad \mathbf{N} \quad \mathbf{F} \quad \mathbf{O}$}

\section{Corresponding Author:}

Suroshree Mitra, Department of Community Physiotherapy, Sancheti College of Physiotherapy, Pune, Maharashtra, India

E-mail Id:

drsurmitra@gmail.com

Orcid Id:

https://orcid.org/0000-0002-6677-8195

How to cite this article:

Shah MJ, Mitra S, Dabadghav R. Screening Higher Secondary School Adolescents for Factors Contributing to Stress in Pune City. Ind J Youth Adol Health 2019; 6(3): 43-49.

Date of Submission: 2020-03-11

Date of Acceptance: 2020-04-25

\section{$\begin{array}{llllllll}\mathbf{A} & \mathbf{B} & \mathbf{S} & \mathbf{T} & \mathbf{R} & \mathbf{A} & \mathbf{C} & \mathbf{T}\end{array}$}

Introduction: Adolescence is a very formative time. The individual goes through a phase of changing from a child to an adult.Mental health conditions account for almost $16 \%$ of the global burden of disease and injury in individuals belonging in the age group of 10-19 years and half of all these conditions start by 14 years of age. Various factors such as hormonal changes, academic performance, participation in extracurricular activities, family background, socio economic status, peer pressure, etc., can contribute to the level of stress perceived by the adolescent.

Materials and Methodology: A total of 385 higher secondary school students (males and females) who signed the assent were included. The $3 S Q$ was given to higher secondary school students $(n=385)$ to assess the possible sources of stress. $3 \mathrm{SQ}$ represents 44 possible sources of stress in students identified from the literature divided in domains like academic, interpersonal, intrapersonal, group social, learning and teaching and teacher related stressors. Descriptive analysis of the data obtained was done.

Result: Out of the 385 students, $29.13 \%$ reported for mild stress due to academic stressors and almost $7.21 \%$ reported for severe stress. $38.26 \%$ and $11.9 \%$ reported for mild and severe stress respectively due to interpersonal related stressors.

Conclusion: Thus, the authors conclude that majority of the students reported to perceive mild to severe stress due to academic related stressors and interpersonal related stressors. They also perceived stress due to other factors but comparatively in a lesser amount.

Keywords: Mental Health, Stress, Adolescents, Physiotherapy

\section{Introduction}

Adolescence is a very formative time. The individual goes through a phase of changing from a child to an adult. Adolescent is that age group where the individual undergoes not only physiological and physical change but also psychological and emotional changes.

According to the World Health Organization, mental health is a state of well-being in which the individual is capable to cope 
with the normal stresses of life, knows his or her abilities, can work in a productive and fruitful manner, and thus is able to make a contribution to his or her community." Mental health conditions account for almost $16 \%$ of the global burden of disease and injury in individuals belonging in the age group of 10-19 years and half of all these conditions start by 14 years of age. Approximately $10-20 \%$ of adolescents do experience mental health problems worldwide, out of which depression being the most common, these often remain undiagnosed and undertreated. ${ }^{1}$

Stress is a feeling due to any emotional or physical tension. Stress can be associated due to any event or thought that makes one feel frustrated, angry, or nervous. Prolonged exposure to stress may be the cause of behavioral changes in adolescents. ${ }^{2}$ Various factors such as hormonal changes, academic performance, participation in extracurricular activities, family background, socio economic status, peer pressure etc can contribute to the level of stress perceived by the adolescent. Excessive parental control, poor teacherstudent relationship, unsuitable school or home environment have a effect on the student's self-esteem and was also associated with anxiety and depression. ${ }^{3,4}$ Moreover anxiety, depression, eating disorders, sleep disturbances, attempts to suicide due to stress etc are also very common in the individuals of this age group. ${ }^{5,6}$

Adolescent's mental health is highly impacted if they are exposed to major risk factors for a prolonged period of time. Their impaired relationships with their friends and family due to constant bullying or harsh parenting (in the form of physical or verbal abuse), respectively, may serve as risk factors for affecting the child's mental health and well- being. Each individual's perception of stress is different depending on different stressors. The way they deal with the stress also differs.Screening the adolescents for sources of stress and helping them to cope with stress thus becomes important. Health promotion is an important domain of physiotherapy. It has been proven previously that physiotherapy does have a role in mental health promotion as well. ${ }^{7}$ Physical therapy does play a very important role in helping these adolescents to reduce their stress levels through yoga, meditation, mind and body relaxation techniques and various other strategies. ${ }^{8}$ Regular practice of meditation has proved to reduce anxiety and improve academic performance in adolescents with learning disabilities. ${ }^{9}$ Regular exercises may act as a stress buster and thus aid adolescent's mental health by reducing stress levels. ${ }^{10}$ This led the authors to the need to assess the students in order to help prevent them from becoming stressed adults and provide them with a healthy adulthood experience, if prompt measures would be taken to promote their mental as well as physical health.

\section{Methodology}

This is a preliminary cross-sectional study. Higher secondary school adolescents were recruited by purposive sampling technique from English medium high schools located in different areas of Pune city.

Students belonging to the age group of 13 to 16 years (mean age $=14.48$ years, $S D \pm 0.8$ ) were included in the study. Special children of this age group and students who did not sign the assent form were excluded from the study. These students were recruited from 3 English medium high schools of Pune. All the students belonged to different areas of Pune city, India. Permission to conduct this study was obtained from the Institutional Ethical Committee and from the schools, prior to the start of this research study. Written consent was obtained from the principals of these schools after explaining the aims and the objectives of the research study. Written assent from every student was taken and the need of the study was verbally explained to them. A total of 385 students signed the assent and became a part of the study.

The Secondary School Stressor Questionnaire (3SQ) was used as the outcome measure by the investigator. The 3SQ was helpful to identify stressors of secondary school students. ${ }^{11}$ The items in 3SQ represent 44 possible sources of stress in secondary school students identified from the literature. ${ }^{12}$ It was a self-reporting questionnaire. Students were asked to answer each question by choosing from five responses: 'causes no stress at all,' 'causes mild stress,' 'causes moderate stress,' 'causes high stress' and 'causes severe stress.' Every student was given a copy of the questionnaire. Basic demographic data like name of the school, student's name, age, gender, standard was also taken. The time taken by the students for filling in the questionnaire was around 15 to 20 minutes. After the completion of the questionnaire, the forms were collected back on the same day by the investigator.

A descriptive analysis of the data obtained was done. Total percentage of every response of the Likert scale (no stress, mild stress, moderate stress, high stress, severe stress) of each of the 44 possible sources was calculated. Later on the total percentage of responses for no stress, mild stress, moderate stress, high stress, severe stress in every domain (academic related, interpersonal related, intrapersonal related, group social related, learning and teaching related, and teacher related) was calculated based on the total number of factors in each domain.

\section{Result}

A total of 385 students participated in the study. Both males and females were included.

Table 1, includes the number of students belonging to a particular age group and gender.

Table 2 consists of the results obtained by descriptive analysis of the data collected. 
Table I.Demographic information

\begin{tabular}{|c|c|c|c|c|c|c|}
\hline Standard & \multicolumn{2}{|c|}{$\mathbf{8}^{\text {th }}$ Std $\mathbf{1 3 - 1 4}$ years } & \multicolumn{2}{c|}{$\mathbf{9}^{\text {th }}$ Std $\mathbf{1 4 - 1 5}$ years } & \multicolumn{2}{c|}{$\mathbf{1 0}^{\text {th }}$ Std 15-16 years } \\
\hline Gender & Males & Females & Males & Females & Males & Females \\
Number of Students & 22 & 50 & 109 & 103 & 45 & 56 \\
\hline
\end{tabular}

Table 2.Stress perceived in particular stressor domain

\begin{tabular}{|c|c|c|c|c|c|}
\hline Stressor Domain & $\begin{array}{c}\text { Responses } \\
\text { for no } \\
\text { stress (in \%) }\end{array}$ & $\begin{array}{c}\text { Responses } \\
\text { for mild } \\
\text { stress (in \%) }\end{array}$ & $\begin{array}{c}\text { Responses } \\
\text { for moderate } \\
\text { stress(in \%) }\end{array}$ & $\begin{array}{c}\text { Responses } \\
\text { for high } \\
\text { stress (in \%) }\end{array}$ & $\begin{array}{c}\text { Responses for } \\
\text { severe stress } \\
\text { (in \%) }\end{array}$ \\
\hline Academic Related Stressors & 22.04 & 29.13 & 22.48 & 19.08 & 7.21 \\
\hline Interpersonal Related Stressors & 48.99 & 38.26 & 26.57 & 17.97 & 11.9 \\
\hline Intrapersonal Relates Stressors & 16.21 & 12.48 & 8.9 & 6.99 & 4.37 \\
\hline Group Social Related Stressors & 19.49 & 7.86 & 4.54 & 2.45 & 1.47 \\
\hline Learning and Teaching Related Stressors & 10.97 & 10.71 & 7.13 & 4.22 & 2.44 \\
\hline Teacher Related Stressors & 2.92 & 2.9 & 1.61 & 1.02 & 1.1 \\
\hline
\end{tabular}

\section{Discussion}

The main purpose of this study was to find out what are the major sources to stress amongst higher secondary school adolescents. From the analyzed data it was found that higher secondary school adolescents perceive mild to severe stress due to academic related and interpersonal related stressors. School related stressors affect the child's psychology and are associated with psychosomatic complaints and musculoskeletal pain. ${ }^{13}$

The education system of India includes mainly Central board of Secondary Education (CBSE), Council for the Indian School Certificate Examinations (CICSE) etc. and the other being the State Board which is governed by the respective states. Mainly the syllabus is such that majority of examination pattern expects the students to memorize the lessons. The pattern is more textbook oriented along with some practical orientation. Students who are unable to learn the expected content or have difficulty in understanding the content find examinations stressful and getting poor results in turn reduces their self esteem.Moreover, due to ever increasing population of children in India, the ratio of teacher-student is very disproportionate leading to crowded classrooms and increased competition. These adolescents also face the fear of not getting admission in the desired institution and the desired stream for higher education. This may be due availability of less number of institutes as compared to the number of students competing to take admission in those institutes. Families may force the child to a particular stream which may not be desired by the student. ${ }^{14}$

Adolescents spend a major portion of the day in schools. Factors like competitive learning environment, getting poor marks, examination, difficulty in understanding the content to be learnt etc. are found to be major contributors for stress in adolescents in this study. These factors may be the sources of their stress due to high expectations for better academic performance imposed on them by their parents or teachers. ${ }^{[15]}$ In order to perform better in academics, thereis an increase in the burden for extra tuitions thus they are left with very little time for recreational activities.

If the child is unable to meet his parent's or teacher's expectations, it may increase their conflicts with them thus straining the interpersonal relations. Previous study has also proven that stress can be the cause of undesirable behavior among adolescents. Along with the academic related stressors, factors like conflict with peers, verbal abuse done by peers, family or teachers, crowded classrooms etc have shown to contribute stress in significant amount. The reasons can be lack of support during this transitional phase of a child to an adult, lack of child's ability to express his/ her feelings or to have effective communication skills etc. It is found that lack of self esteem or motivation to learn can be the reasons for significant stress. Quality of peer interactions at school has an effect on the adolescent's perception on health and their well-being. ${ }^{13}$

Studies show a significant relationship between stress and peer pressure. Any conflict with peers, bullying, and inappropriate behavior by them can contribute to their stress. Any increase in frustration and stress amongst these adolescents can increase if they seek out to wrong peer groups to have a sense of belonging. ${ }^{16}$

On the other hand, positive and encouraging environment for participation in group activities have been shown to reduce the stress perceived during social interactions. Also, nowadays teachers understand a child's psychology and their better personality traits, friendly nature, active participation and enthusiasm to teach may have a positive 
impact on student's perception towards them. Therefore, less percentage of students reported stress due to teacher or teaching related stressors. ${ }^{17}$

With age, various factors contributing to stress will be different and will definitely increase. After completing Grade $11^{\text {th }}$ and Grade $12^{\text {th }}$, they will have to look forward for achieving higher education. They will have to search for better job opportunities so that they are able to provide a better financial status to their families. There are certain factors or stressors that cannot be modified or avoided. But, with the present study, as the authors were able to find out the major stressors, it will become easier to target this population and help them to develop appropriate and effective coping strategies.

Schools, families and the community in general should provide the child with supportive environment so as to enable the child to grow mentally healthy. A lot of factors play a role for various mental health outcomes. Stress can be managed in an effective way by adopting healthy sleep patterns, taking regular exercise, developing coping, problem-solving, developing interpersonal skills and learning to manage emotions etc. ${ }^{1}$

If this population learns the way to cope with the various stressors at an early age, they will be able to deal with the future upcoming unavoidable stressors in an effective manner and thus will protect them from facing mental health issues like stress, anxiety, depression etc. They can be encouraged to make exercises as a part of their lifestyle right from this age as studies have shown that various forms of daily physical activity has an effect on the child's psychology, overall well being, good physical health and in turn reduce absenteeism in school, increase enthusiasm towards learning and promote positive thinking towards oneself.

Future scope of the study: A follow up intervention based study can be done. Exercise intervention can be given to these students and the amount of stress perceived post intervention can be assessed due to these various stressors.

Clinical implication: Physiotherapy interventions can be used for mental health promotion in adolescents. Physiotherapists can become a part of the multi-disciplinary team to treat mental health issues. These children can be educated right from this age about the importance of making exercise as a part of their lifestyle and thereby using exercise as a stress buster. Yoga, meditation, general mind and body relaxation techniques can be used in improving cognitive process of brain i.e. to improve attention, perception, observation, memory and overall general well being of the student.

\section{Conclusion}

Based on the results, the authors conclude that higher secondary school adolescents do perceive significant amount of stress due to various stressors. Out of them academic and interpersonal related stressors are found to be major sources of their stress. Students do perceive stress due to other stressors as well, but comparatively to a lesser extent.

\section{Acknowledgement}

The authors would like to take this opportunity to thank theprincipal and the teachers for spending their valuable time and granting us the permission to recruit students from their schools. We would also like to thank all the participants who volunteered to become the part of this study. We thank Dr. Parag K. Sancheti sir (MS Orthopedics), Dr. Ashok Shyam sir (Research Officer and MS Orthopedics) Dr. Apurv Shimpi (PT), Professor and HOD of Community PT Dept. and the Institutional Ethical Committee of Sancheti Institute for Orthopedics and Rehabilitation, for their constant support and guidance in conducting this research study.

\section{Conflict of Interest: None}

\section{References}

1. World Health Organization, Adolescent Mental Health. Available from: https://www.who.int/news-room/factsheets/detail/adolescent-mental-health. Accessed in March 2020.

2. Romeo RD. The teenage brain: The stress response and the adolescent brain. Current directions in psychological science 2013 ; 22(2): 140-145.

3. Eccles JS, Midgley C, Wigfield A, Buchanan CM, Reuman $D$, Flanagan $C$ et al. Development during adolescence: The impact of stage-environment fit on young adolescents' experiences in schools and in families (1993).

4. Moksnes UK, Moljord IE, Espnes GA, Byrne DG. The association between stress and emotional states in adolescents: The role of gender and self-esteem. Personality and Individual Differences 2010; 49(5): 430-435.

5. Mikolajczyk RT, El Ansari W, Maxwell AE. Food consumption frequency and perceived stress and depressive symptoms among students in three European countries. Nutrition Journal 2009; 8(1): 31.

6. Shaikh BM, Doke PP, Gothankar JS. Depression, anxiety, stress, and stressors among rural adolescents studying in Pune and a rural block of Nanded district of Maharashtra, India. Indian journal of public health 2018; 62(4): 311.

7. Everett T, Dennis M, Ricketts E, editors. Physiotherapy in mental health: A practical approach. ButterworthHeinemann; 2013; 22.

8. White LS. Reducing stress in school-age girls through mindful yoga. Journal of Pediatric Health Care 2012; 26(1): 45-56.

9. Beauchemin J, Hutchins TL, Patterson F. Mindfulness meditation may lessen anxiety, promote social skills, 
and improve academic performance among adolescents with learning disabilities. Complementary Health Practice Review 2008; 13(1): 34-45.

10. Brown JD, Siegel JM. Exercise as a buffer of life stress: a prospective study of adolescent health. Health psychology 1988; 7(4): 341.

11. Yusoff MS. The validity and reliability of secondary school stressor questionnaire (3SQ) in identifying stressor among adolescents in secondary school. International Medical Journal 2011; 18(2): 99-105.

12. Yusoff MS. Stress, stressors and coping strategies among secondary school students in a Malaysian government secondary school: Initial findings. ASEAN Journal of Psychiatry 2010; 11(2): 1-0.

13. Murberg TA, Bru E. School-related stress and psychosomatic symptoms among Norwegian adolescents. School psychology international 2004; 25(3): 317-332.

14. Deb S, Strodl E, Sun J. Academic stress, parental pressure, anxiety and mental health among Indian high school students. International Journal of Psychology and Behavioral Sciences 2015; 5(1): 26-34.

15. Sangma ZM, Shantibala K, Singh B. Perception of Students on Parental And Teachers' Pressure on Their Academic Performance. Avaliable from: https://www. semanticscholar.org/paper/Perception-of-Students-onParental-And-Teachers-\%E2\%80\%99-*-Sangma-Shanti bala/6555bd10a83f942f6505f2bb47b6a3ce6c951af9

16. Bwire TW. Stress, peer pressure and substance abuse among adolscents in Luzira (Doctoral dissertation, Makerere University).

17. Eryilmaz A. Perceived Personality Traits and Types of Teachers and Their Relationship to the Subjective WellBeing and Academic Achievements of Adolescents. Educational sciences: Theory and practice 2014; 14(6): 2049-2062. 


\section{Questionnaire}

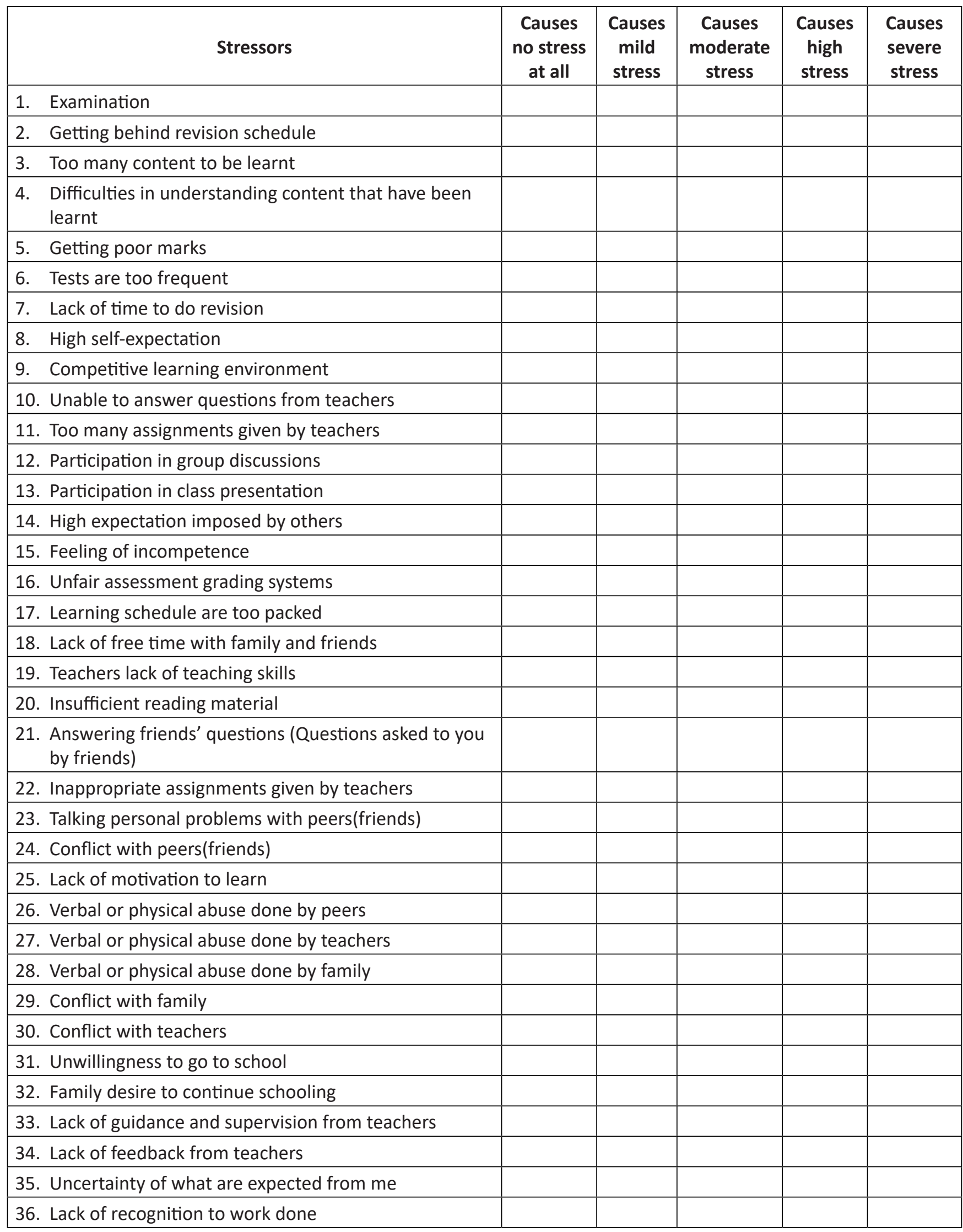




\begin{tabular}{|l|l|l|l|l|l|}
\hline 37. Family desire to stop schooling & & & & & \\
\hline 38. Interruptions by others during learning & & & & & \\
\hline 39. Studying for the sake of family & & & & & \\
\hline 40. Crowded classroom & & & & & \\
\hline 41. Negative thinking toward own-self & & & & & \\
\hline 42. Came late to the school & & & & & \\
\hline 43. Giving wrong answer in the class & & & & & \\
\hline $\begin{array}{l}\text { 44. Afraid of the possibility not getting place in any } \\
\text { university }\end{array}$ & & & & & \\
\hline
\end{tabular}

